\title{
Research
}

\section{Attitudes of newly qualified doctors towards a career in general practice:}

\author{
a qualitative focus group study
}

\begin{abstract}
\section{Background}

A key element of the NHS is universal access to a GP. Recently, UK general practice has been described as being in crisis, with training places unfilled and multiple practices reporting vacancies or facing closure. The recruitment of GPs continues to be a key focus for both the Royal College of General Practitioners (RCGP) and the government.
\end{abstract}

\section{Aim}

To understand the attitudes of newly qualified doctors towards a career in general practice, to appreciate potential reasons for the crisis in GP recruitment, and to recommend ways to improve recruitment.

\section{Design and setting}

A qualitative study comprising five focus groups with 74 Foundation Year 1 (FY1) doctors from one Yorkshire deanery.

\section{Method}

Audio recordings were transcribed verbatim and thematic analysis undertaken

\section{Results}

Foundation Year 1 doctors thoughts towards a career in general practice were summarised in four themes: quality of life, job satisfaction, uncertainty surrounding the future of general practice, and the lack of respect for GPs among both doctors and the public. Participants felt that general practice could provide a good work-life balance, fair pay, and job stability. Job satisfaction, with the ability to provide care from the cradle to the grave, and to work within a community, was viewed positively. Uncertainties around future training, skill levels, pay, and workload, together with a perceived stigma experienced in medical schools and hospitals, were viewed as a deterrent to a career in general practice.

\section{Conclusion}

This study has gathered the opinions of doctors at a critical point in their careers, before they choose a future specialty. Findings highlight areas of concern and potential deterrents to a career in general practice, together with recommendations to address these issues.

\section{Keywords}

career choice; general practice; job satisfaction newly qualified; primary health care; recruitment; retention.

\section{INTRODUCTION}

A key element of the NHS since its inception in 1948 has been access to a GP, hence the recruitment and morale of GPs has been, and continues to be, a key focus of government policy. General practice, however, has recently been described as being in crisis due to changes in demand and supply of care. 'Patient demand for GP consultations has grown significantly, with an estimated increase of 40 million consultations a year since 2008. ${ }^{2}$ This increased demand is compounded by the current difficulties in the recruitment and retention of GPs. The British Medical Association, for example, has repeatedly stated that the UK is facing a serious shortfall in the number of GPs. ${ }^{3}$ This is supported by findings from Health Education England that show that one in eight GP training posts remain unfilled. ${ }^{4}$

There have been a limited number of studies in the UK that focus on the opinions of students, junior doctors, and GPs as to the reasons for the current recruitment crisis. $^{5-8}$ These studies portray a mixed picture. Some suggest participants have a positive attitude towards a career in general practice, ${ }^{7}$ although others highlight more negative aspects. ${ }^{5}$ Lifestyle, organisational factors, and the influence of hospital medicine emerged consistently across these papers. One study that surveyed participants' future career plans found that only $13 \%$ of participants identified general practice as their first career choice, compared with 85\% whose first career choice was a hospital specialty.

The aim of this study is to add to the current knowledge base by exploring the attitudes towards general practice of newly qualified doctors in the Yorkshire and the Humber region, including urban and rural placements. This area has one of the lowest levels of GP recruitment in England. ${ }^{9}$ The authors provide further insight into the perceived problems with general practice, compare the findings with previous studies, and recommend ways to improve GP recruitment.

\section{METHOD}

Seventy-four Foundation Year 1 (FY1) junior doctors attended a medical careers day in early 2016 as part of their protected time for learning. During the general practice session, the junior doctors were invited to take part in a group discussion to explore their thoughts and attitudes towards a career in general practice.

The FY1 doctors had spent the first 6 months of their careers on hospital wards in Hull, York, Scarborough, Scunthorpe, and Grimsby (North Yorkshire and East Coast [NYEC] Foundation Schooll. Hence, they based their opinions on their experience of placements in medical schools across the UK. A semi-structured topic schedule was designed and facilitated in each group exercise.

A study information sheet was provided
A Merrett, BSc, year 4 medical student, Hull York Medical School, University of Hull. D Jones, MBChB, locum GP, PhD student; K Sein, MSc, PhD student; T Green, PhD, senior research fellow; U Macleod, PhD, FRCGP, FHEA, professor of primary care medicine, Centre for Health and Population Sciences, Hull York Medical School, University of Hull.

Address for correspondence

Alexandra Merrett, Hull York Medical School,
University of Hull, Cottingham Rd, Hull, HU6 7RX, UK.

E-mail: Hyam7ahyms.ac.uk

Submitted: 15 August 2016; Editor's response: 31 August 2016; final acceptance: 14 October 2016. @British Journal of General Practice This is the full-length article (published online $31 \mathrm{Mar} 2017)$ of an abridged version published in print. Cite this version as: Br J Gen Pract 2017; DOl: https://doi.org/10.3399/bjgp17X690221 


\section{How this fits in}

In the UK, general practice has suffered a decline in recruitment, an important issue for both the Royal College of General Practitioners (RCGP) and the government. There have been a limited number of studies in the UK that focus on the opinions of students, junior doctors, and GPs as to the reasons for the current recruitment crisis. Foundation Year 1 (FY1) doctors thoughts towards a career in general practice were obtained and summarised into four key themes. The authors' findings offer some insight into the reasons for the current crisis, and provide potential solutions to increase the future recruitment of GPs.

to participants, and written consent was obtained for the audio recording of each group exercise. These were then professionally transcribed verbatim. Participation was voluntary and no one refused consent or withdrew.

A thematic analysis was conducted using NVivo, due to the openness of the questions posed and the structure of the groups. ${ }^{10,11}$ To ensure analytic rigour, three separate researchers conducted independent analysis, before combining and crosschecking the findings.

Two researchers analysed all five groups, while the third analysed two groups. The superordinate and ordinate themes created were checked and compared, before a consensus was reached on which themes should be included in the final analysis.

\section{RESULTS}

The 74 FY1 junior doctors from the NYEC Foundation School were divided into five groups, ranging from eight to 20 participants. Throughout the transcripts, four main themes were identified: perceived quality of life when working as a GP, perceived job satisfaction, uncertainty surrounding the future of general practice, and the lack of respect for GPs among both doctors and the public. Within each of these themes there were emergent sub-themes, which are presented below, along with illustrative quotes.

\section{Perceived quality of life in general practice}

The perceived quality of life in general practice was addressed in all five groups and was the first topic raised for discussion in three groups.

The emerging sub-themes included worklife balance, rates of pay, and job stability:
I'm not the type of person that would sacrifice life and work, and I think general practice is one of those specialties which you can go in which you've got a good balance of both.' (Participant, group 3)

Some participants stated that a GP's role might become more attractive later in their careers, particularly when considering the demands of a family. Others perceived a career in general practice to be a more 'relaxed' option, with less focus on academic advancement and excitement:

I don't really want to do it, but thinking towards the future, having a bit more of a relaxed lifestyle because you can more control the time, can't you? So, having a family, people always say that general practice is a good way to go.' (Participant, group 4)

I know GPs have routine, per se, unless you get the exciting: "Oh, this patient might have meningitis, I'd better ring an ambulance." That's the most exciting it gets. '(Participant, group 2)

In four out of five groups, participants stated that general practice was more difficult than they had initially anticipated. Moreover, participants emphasised that general practice was potentially as stressful as any other specialty:

When I was working at [sic] GP, they actually worked really long hours, and the lifestyle didn't seem that much better. (Participant, group 2)

'They all work a hell of a lot harder than anybody realises.' (Participant, group 2)

Despite concerns about potential workload, the majority of participants perceived that a career as a GP would provide a better quality of life. The comparative downsides of working as a hospital clinician were often more compelling, and administrative issues were raised in three groups:

'I just can't imagine myself running after secretaries and stuff for the rest of my life. I think it's just the whole sort of packet, rules and regulations within hospitals, you can't do certain things without certain people's signatures, and you can't do this without that.' (Participant, group 1)

\section{Perceived job satisfaction}

Participants in all five groups spoke frequently of the high level of job satisfaction achieved in 
general practice. This was the first topic raised in two of the groups.

Elements discussed included clinical aspects, such as the continuity of care delivered, the breadth of general practice, and the sense of being part of a community, and practical aspects, such as the flexibility of general practice and the ability to run a business.

The ability to provide continuity of care spanning many generations was unanimously considered an attractive feature of general practice. The participants believed this helped build the doctor-patient relationship:

I like the fact that I could build up a picture of the family dynamic. Then you'd always have something to talk about from their last appointment, and / think it's more enjoyable when you can see the work you've done is going well, and the fact that you can remember them makes the next consultation easier, because you've already got a foot in.' (Participant, group 4)

Participants stated that acting as a gatekeeper allowed for a varied caseload across all aspects of medicine, which they considered an exciting and challenging prospect.

A number of participants, however, articulated some reluctance towards the prospect of managing patients with mental health problems, and/or those with what they perceived to be social rather than medical needs:

Every single patient that came in wasn't really with a medical condition. It was more psychosocial, and so I can understand why a lot of my friends were, like: "I would never do this. Why have I spent 5 years learning all about the body, the anatomy, everything, and it's my psychiatrist or psychologist role used?"' (Participant, group 5)

Furthermore, some participants believed that as a GP they would be left without a specific skillset. Participants commented that this meant they were unable to provide expert advice and support, and were merely facilitating care:

In a sense, it's the hardest job in medicine, because you can't know everything about everything. But I think it's hard to have an expert opinion, or know exactly what to do with a lot of patients.' (Participant, group 2)

Participants recognised the value of teamwork, but did not agree on the extent of this in general practice.

Some participants perceived that GPs were an important part of a team within the community. Others viewed general practice as a 'lonely' specialty, without the support and 'team spirit' that hospitals offer:

'It's a lot scarier, because you're more on your own for a long time. Yeah, you might work in a general practice with other GPS, but you could just be working as a GP on your own, on an island somewhere, no one else to speak to, and that's quite scary. (Participant, group 4)

The opportunity to work as a GP with a Special Interest (GPwSI) was frequently mentioned. This was unanimously viewed as a positive aspect of general practice, because it provided the opportunity to focus on individual medical interests and specialties:

.... the prospect of being a GP with a special interest, so you can focus on things that you really do enjoy.' (Participant, group 2)

I know a GP with a special interest in dermatology, and she was saying that it means that she gets to do GP, and she gets to do something else as well. Although, it did make me smile that the thing that she likes about being a GP is that she can not be a GP for a bit.' (Participant, group 4)

Lastly, being able to run a business as a GP was discussed by all five groups, although it was perceived in both a positive and a negative light.

A minority of participants identified that GPs were allowed the autonomy to choose their own lifestyle and develop a new skillset, but the majority of participants disagreed. These latter commented that the aim was no longer patient care, but meeting quotas and targets. They felt that general practice was more about business, and as GPs they were no longer practising medicine. Running a business in a time of uncertainty was also viewed unfavourably. Participants felt that there was little guidance on setting up and managing a business:

If you were seeing patients all day, fine. But it's the extra time - the 4 hours lunchtime that you're not having lunch ... it's the other bits and pieces you've got, relating to QOF [Quality and Outcomes Framework] points, relating to managerial work, because general practice partners are also business people, really. It's all that, and that's not medicine.' (Participant, group 3) 


\section{Uncertainty regarding the future of general practice}

The uncertainties facing general practice were raised by participants in all five sessions and were viewed negatively. The emergent sub-themes included future uncertainty around training, skill levels, pay, and workload.

Participants noted the uncertainty arising from increased litigation, which was considered to significantly increase work stress and the likelihood of burning out. Furthermore, participants felt that the threat of litigation increased the need to make an accurate diagnosis, and that this would result in more referrals to consultants:

Yeah. I've come across GPs that are going through, like, litigation processes, and have been absolutely burnt out with it. I think everyone at some point, whatever specialty, will miss a diagnosis. But you're much more open to litigation in general practice. (Participant, group 3)

Uncertainty regarding the length of the GP training was discussed in two groups. Some participants found that the current 3-year training scheme was a positive factor, because it allowed junior doctors a secure, established employment much earlier than any other hospital specialty. Conversely, other participants perceived that a longer training scheme would increase their knowledge as a generalist, increase their competencies, and give them more time in a hospital setting:

'You only have 3 years, and there's only so much you can really fit in. Then that's kind of your end game, and you can do a special interest and go in for other things. But if it was 4 or 5 years, and you got a bit more, sort of, hospital medicine, then I'd probably prefer it. l'd like a bit more experience. (Participant, group 4)

Future uncertainties relating to workload and the impact of government cost-cutting on GP salaries were also raised as issues. The possibility of handing over clinical work to other healthcare staff, uncertainty surrounding working as a GPwSI, and the potential increase in privatisation of the NHS were also discussed:

'It's the whole: "Are GPs going to work weekends? Are they going to work evenings? Is it going to be 24 hours a day, 7 days a week?" With most of the hospital specialists you expect that to an extent, but while it's all in flux I think it's a bit unrealistic to expect lots of people to want to go and do it when you don't know what you're getting. letting yourself in for.' (Participant, group 3)

\section{The lack of respect for GPs}

The perceived 'stigma' of being a GP was a key theme across the data. Some participants who were considering a career in general practice commented that they were ashamed to mention this in the hospital environment, for fear of prejudicial treatment:

I think that they [GPs] don't get a lot of respect, and that people just see it as the kind of background of all the specialties. It's where everyone else gets put. I don't think even in medical school a lot of people would admire you for saying you wanted to be a GP. I can imagine you would feel quite underappreciated by your colleagues, and by patients, sometimes, as well. I think a lot of people, patients, don't appreciate the work that GPS do as well, and in the media as well ... which I guess must get to you. (Participant, group 5)

Negative comments and perceptions of being a GP had been widely encountered, with some participants stating these were 'everywhere'. This perceived lack of respect constituted a key deterrent to a career in general practice.

The media and patients were perceived as contributing to the stigma, but the most serious prejudice was encountered among clinical staff in medical schools and hospitals:

It happened in medical school as well, few lecturers and stuff, the consultants would have a general dig at the GPS. (Participant, group 1)

Participants commented that hospital staff frequently drew attention to the perceived poor quality of GPs' referrals. Participants also relayed comments they had heard in regard to low academic achievement and poor work ethic among GPs:

I'm on general surgery, and I think surgeons, they do not respect GPs. I think they kind of undermine the GP's potential or achievement in life. They say: "Oh, you only do GP if you're not smart enough." I remember when I was on my ward round, a surgeon just said to me: "The people who do GP are the ones are like the bottom of the year", and I just looked at him. I was so shocked when he said that, because 
that is just an inappropriate comment. (Participant, group 5)

Lastly, some participants had formed a negative perception of general practice from their experiences during placements within primary care. These perceptions deterred them from a career in general practice:

Every time, in medical school, whenever we had to go to a GP practice, the kind of characters I came across, I just saw them and thought: "I hope I never become such a doctor."'(Participant, group 1)

'I felt like they didn't care, because I went through, like, a day where the doctor didn't even touch the patient.' (Participant, group 1)

\section{Participants' recommendations}

Participants were asked how they would address current recruitment problems. A number of recommendations to improve GP recruitment were generally agreed. Participants stated that financial incentives would encourage GP recruitment:

Increase the pay ... because money would attract employment.' (Participant, group 5)

Participants wanted to reduce the perceived non-medical part of the job Ipotentially by providing a personal assistant), and reconfigure the GP contract to eliminate the administrative 'tick box' culture. The establishment of a formal feedback process to improve the quality of the communication between GPs and hospital staff was also recommended:

'I also think that GPs don't get any feedback from us anyway. So, it's almost like: "Why would the GP go to the extra mile if he is never going to hear the compliment?" (Participant, group 1)

\section{DISCUSSION}

\section{Summary}

Participants taking part in the sessions identified four key aspects that affected their opinion of general practice. Perceived quality of life and job satisfaction were generally viewed positively compared with other specialties, although there were concerns that the advantages, such as work-life balance, were being eroded. The uncertainties around the future of general practice and the NHS were viewed negatively. There was a perceived lack of respect for general practice within the medical profession, among the public, and in the media, which the FY1s saw as a significant deterrent against a career in general practice. Overall, although most participants in this study recognised the importance of general practice, few considered it their first career choice. Potential remedies focused on reducing the uncertainties for the future direction of general practice, increased pay, and decreased managerial and administrative workload.

\section{Strengths and limitations}

The use of focus groups was a key strength of the study as it allowed for an interactive discussion, during which positive and negative opinions could be aired. The inclusion of a range of participants, including individuals who were not considering a career in general practice, greatly aided the discussion. As all the participants were FY1 doctors, they were at the point in their training where they would soon be choosing their future specialty. The participants were also working in an area notably hit by the current recruitment crisis.

The study has several limitations. The discussion sessions were run as part of a training seminar instead of being specifically arranged for a research study. This meant the groups were often large, and the identification of individuals in the transcription was not possible. However, as the FY1s all came from the same foundation school, the ability to identify common themes, draw conclusions, and make recommendations was not impacted. Additionally, the groups were not purposively sampled, a practice that would have ensured that the groups were of a more appropriate size. This, however, resulted in the potential inclusion of participants who may not otherwise have attended a group meeting for the purposes of research.

\section{Comparison with existing literature}

These results are comparable with the Chellappah and Garnham study in 2014 conducted with medical students.? Participants in that study had a generally positive attitude towards general practice, but considered it a less prestigious career than hospital specialties.

Petchey et al in 1997 looked at junior doctors' attitudes towards general practice. ${ }^{5}$ The participants felt that a career in general practice could offer an improved worklife balance, but at the cost of being less clinically challenging, hence providing less job satisfaction. In addition, the negative aspects of working in a hospital (high levels of 
stress, intense competition, unsocial hours) were highlighted, and perceived as more important than the positive characteristics of working in general practice. ${ }^{5}$ The findings were remarkably similar to this study, despite being conducted 17 years apart.

The FY1 doctors' critical views of general practice in this study reflect the conclusions of Doran et al (2016), ${ }^{8}$ who interviewed GPs leaving practice early. These authors found that GPs' perceptions of organisational changes in the role had shifted the focus away from patients towards management, leading to conflicting priorities in the consulting room, and reduced time spent with patients. These changes, combined with 'bullying' and 'blame' cultures in the NHS, led to a third of participants experiencing ill-health, stress and anxiety disorders, and burnout. ${ }^{8}$

\section{Implications for practice}

A key concern of participants considering a career in general practice focused on the current uncertainties surrounding the specialty. NHS England (supported by the RCGP) published its General Practice Forward View in April 2016, which looks to address many of these issues with better funding for general practice, reducing workload by managing demand more effectively, building a wider workforce to support GPs, and providing support for GP wellbeing and resilience. ${ }^{12}$ This plan was supported by the BMA, which developed a locality hub model to support GP surgeries operating at over-capacity, and allow GPs to increase consultation time and decrease the number of appointments. ${ }^{13}$

Measures articulated in the General Practice Forward View may address the issue of lack of respect, including the development of a consultant hotline and advice service, which will enable GPs to develop relationships with hospital specialists, potentially negating the need for onward referral. Furthermore, local consultants are being increasingly invited to speak at GP learning and networking events, potentially decreasing perceived unnecessary referrals, and providing a form of feedback.

The findings of this study suggest more could be done in medical school to encourage students to choose general practice as a career. A recent editorial in the BJGP pushed for increased funding and support of student placements in general practice, and for general practice to be championed within the undergraduate curriculum. ${ }^{14}$ Additionally, medical school GP societies should be further encouraged and supported by both the government and the RCGP.

\section{Funding}

Alexandra Merrett received $€ 600$ and Daniel Jones received $€ 200$ from INSPIRE Vocational Research Summer Projects 2016 to undertake this research.

\section{Ethical approval}

Ethical approval for the study was obtained by the HYMS Ethics Council, Ethics Application number 1512 .

\section{Provenance}

Freely submitted; externally peer reviewed.

\section{Competing interests}

The authors have declared no competing interests.

\section{Discuss this article}

Contribute and read comments about this article: bjgp.org/letters 


\section{REFERENCES}

1. Roland M, Everington S. Tackling the crisis in general practice. BMJ 2016; 352: i942.

2. NHS England. Our 2016/17 business plan. 2016. https://umw.england.nhs.uk/ wp-content/uploads/2016/03/bus-plan-16.pdf (accessed 10 Mar 2017).

3. British Medical Association. BMA responds to new report on locum shortages. 2016. https://www.bma.org.uk/news/media-centre/press-releases/2016/june/ bma-responds-to-new-report-on-locum-shortages (accessed 10 Mar 2017).

4. NHS, Health Education England. Specialty recruitment: round 1 - acceptance and fill rate. 2016. https://hee.nhs.uk/our-work/attracting-recruiting/medicalrecruitment/specialty-recruitment-round-1-acceptance-fill-rate laccessed 10 Mar 2017).

5. Petchey R, Williams J, Baker M. 'Ending up a GP': a qualitative study of junior doctors' perceptions of general practice as a career. Fam Pract 1997; 14(3): 194-198

6. Henderson E, Berlin A, Fuller J. Attitude of medical students towards general practice and general practitioners. Br J Gen Pract 2002; 52(478): 359-363.

7. Chellappah M, Garnham L. Medical students' attitudes towards general practice and factors affecting career choice: a questionnaire study. London J Prim Care (Abingdon) 2014; 6(6): 117-123.
8. Doran N, Fox F, Rodham K, et al. Lost to the NHS: a mixed methods study of why GPs leave practice early in England. Br J Gen Pract 2016; DOI: https://doi. org/10.3399/bjgp16X683425

9. NHS, Health Education England. Targeted enhanced recruitment scheme in England. FAQs for GP applicants (August 2017). 2016. https://gprecruitment. hee.nhs.uk/Recruitment/TERS/England laccessed 10 Mar 2017).

10. Braun V, Clarke V. Thematic analysis. In: Cooper H, Camic PM, Long DL, et al, eds. APA handbook of research methods in psychology, Vol. 2: research designs: quantitative, qualitative, neuropsychological, and biological. Washington, DC: American Psychological Association, 2012: 57-71.

11. Silverman D. Doing qualitative research. 4th edn. London: Sage Publications, 2013.

12. NHS England. General practice forward view. 2016. https://www.england.nhs uk/ourwork/gpfv/ laccessed 10 Mar 2017).

13. British Medical Association. Safe working in general practice. One approach to controlling workload and dealing with the resulting overspill through a locality hub model. 2016. http://www.20160684-GP-safe working-and-locality-hubs.pdf laccessed 10 Mar 2017).

14. McDonald $\mathrm{P}$, Jackson B, Alberti H, Rosenthal J. How can medical schools encourage students to choose general practice as a career? Br J Gen Pract 2016; DOI: https://doi.org/10.3399/bjgp16X685297. 